\title{
A compositional approach to conjunct agreement in Turkish
}

\author{
Y1lmaz Köylü*
}

\begin{abstract}
This article presents novel empirical evidence on verbal agreement patterns observed in conjunction phrases (CPs) in Turkish. To account for the discrepancies observed in native speaker preferences in agreement paradigms in CPs, two experimental tasks were carried out: namely an acceptability judgment task and a forced choice task. Based on the results, it is proposed that there is compositional conjunct agreement in Turkish that takes place in two stages. The agreement relationship is first established between the Agreement head and the coordinated phrase in the syntax. Then, the PF spells out the features of either the coordinated phrase, or the features of the linearly closest conjunct inside the coordinated phrase. I argue that Full Agreement (FA) results from the Spec-head agreement with the CP, whereby the features of both conjuncts are resolved and inherited to the $\mathrm{CP}$ (Johannessen 1996). In Closest Conjunct Agreement (CCA), on the other hand, the agreeing head has asymmetric access to one of the prominent conjuncts or its features (Bošković 2009; Johannessen 1998; Munn 1993, 1999; Benmamoun 1992). Thus, in CCA in Turkish, the agreement is with the linearly closest conjunct and the features of that conjunct appear on the verb.
\end{abstract}

Keywords. conjunct agreement; conjunction phrases; coordination; Turkish

1. Introduction. Turkish displays the following agreement patterns in CPs. Items (1) - (3) have identical meanings.

$\begin{array}{ccccl}\text { (1) } & \text { sen } & \text { ve } & \text { o } & \text { git-ti-niz } \\ \text { you } & \text { and } & \text { s/he } & \text { go-PAST-2PL } \\ \text { (2) } & \text { sen } & \text { ve } & \text { o } & \text { git-ti } \\ \text { you } & \text { and } & \text { s/he } & \text { go-PAST.3SG } \\ \text { (3) } & \begin{array}{l}\text { ?sen } \\ \text { yo }\end{array} & \text { o } & \text { git-ti-n } \\ \text { you and } & \text { s/he } & \text { go-PAST-2SG } \\ \text { 'You and s/he went.' } & \end{array}$

(1) exhibits Full Agreement (FA); (2) exhibits Closest Conjunct Agreement (CCA), since the verb agrees with the conjunct that is linearly more proximate; and (3) exhibits Distant Conjunct Agreement (DCA) ${ }^{1}$. While (1) is completely acceptable to most native speakers of Turkish, (2) is

\footnotetext{
* I would like to thank Indiana University, Department of Linguistics, and Department of Second Language Studies for their generous travel funds to the $92^{\text {nd }}$ Annual Meeting of the LSA, where I presented this paper. Special thanks to Steven Franks for stimulating my interest in coordination, as well as the audience at LSA 92 for their insightful comments and suggestions.

${ }^{1}$ In the conjunct agreement literature, one can find two terms I avoid using in this paper. These are (a) First Conjunct Agreement (FCA); and (b) Last Conjunct Agreement (LCA). Since the concepts of first and last can mean both the closest and the distant conjunct depending on whether the verb precedes or follows the CP, I use the terms Closest Conjunct Agreement (CCA) and Distant Conjunct Agreement (DCA) in addition to Full Agreement (FA) to better disambiguate the structural position of the conjuncts in relation to the verb.
} 
relatively less acceptable and (3) is somewhat unacceptable.

The questions I address in this article are whether empirical evidence provide support for the intuitions of native speakers of Turkish in terms of which verbal agreement patterns are acceptable in CPs and what accounts for the (un)acceptability of different agreement patterns in CPs in Turkish. My proposal is that the conjunction agreement patterns in Turkish can be explained by a compositional account that takes place in two stages. According to this compositional account, the agreement relationship is first established between the Agreement head and the CP in the syntactic component. Following this, the PF spells out the person and number features of either the $\mathrm{CP}$ as a whole, or the features of the linearly closest conjunct inside the CP (similar accounts can be found in Bhatia 2011; Franck, Vigliocco, and Nicol 2002; Ackema and Neeleman 2004; Haskell and MacDonald 2005; Benmamoun and Lorimor 2006).

2. Background and previous proposals on conjunct agreement. A conjunction phrase $(\mathrm{CP})^{2}$ is a syntactic constituent consisting of two or more units called conjuncts. The element linking the conjuncts is called a coordinator. Early attempts proposed a flat, multiple branching structure for CPs (Gazdar et al. 1985; Sag et al. 1985; Pullum and Zwicky 1986; Ingria 1990; Pollard and Sag 1994). Recent work, however, treats conjunctions/coordinators as heads of a phrase in a binarybranching structure, typically the conjunction phrase. This is due to the impossibility of stranding of external conjuncts, existence of interactions between coordinators and internal conjuncts, as well as possibility of extraction from either internal or external conjuncts (Zhang 2009).

Zhang (2009) argues that the external and the internal conjunct are in a Spec-Complement relationship with the head realized by the coordinator as shown below (similar accounts in Munn 1987; Larson 1990; Johannessen 1998; and Zoerner 1995).

(4) The complementation structure of CPs in head initial and head final languages
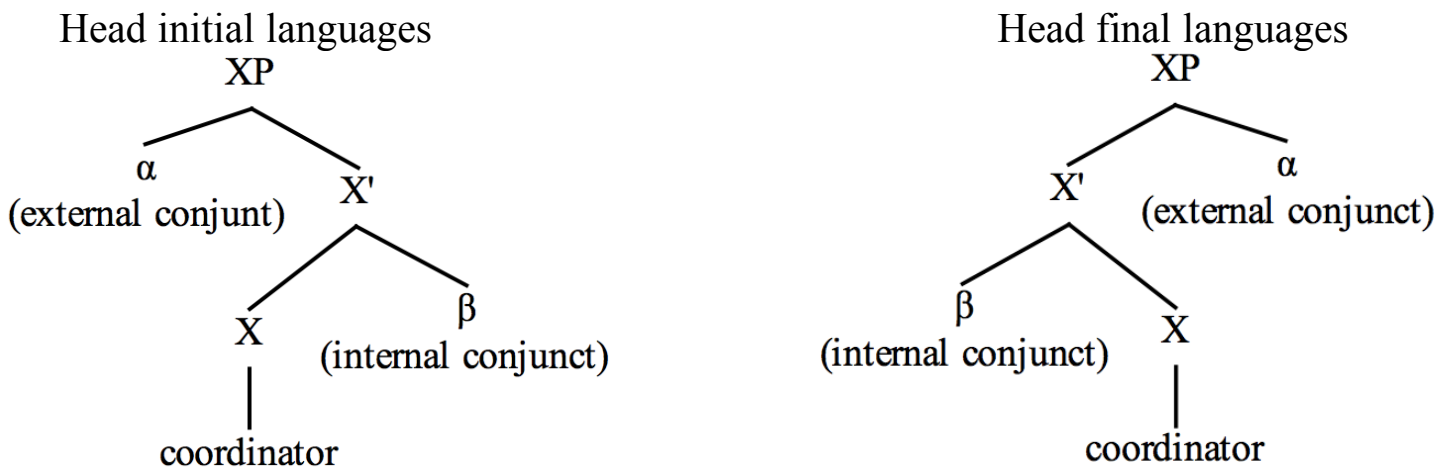

\subsection{TWO APPROACHES ON THE NATURE OF COORDINATION}

2.1.1. CLAUSAL COORDINATION. According to this approach, all conjuncts are clausal, and non clausal conjuncts are the result of reduction (Hudson 1970; George 1980; Goodall 1987;

\footnotetext{
${ }^{2}$ Zhang (2009) argues against a CP claiming that coordinators do not have intrinsic categorial features, and it is the conjuncts that provide the categorial features to them since the category of a $\mathrm{CP}$ is identical to that of at least one of the conjuncts. Zhang (2009) maintains that the notion coordination is not primitive in syntactic computation and thus there is no special category in coordination.
} 
Hoekstra 1994; Johannessen 1998; Aoun et al. 1994; Aoun and Benmamoun 1999; Camacho 2003). Consider the examples below which show how grammatical sentences are derived from underlying forms under a clausal coordination account. The (d) sentences represent the underlying forms while the (a) sentences are the surface representations.

(5) a. Emily and Amy study linguistics.

b. *Emily and Amy studies linguistics.

c. *Emily studies linguisties-and Amy studies linguistics.

d. Emily studies linguistics and Amy studies linguistics.

(6) a. Max and Ashley are a cute couple.

b. *Max and Ashley is a cute couple.

c. *Max is a cute couple and Ashley is a cute couple.

d. *Max is a cute couple and Ashley is a cute couple.

As illustrated in (5) and (6), a clausal coordination analysis requires two operations: deletion and regrouping. Nevertheless, such a clausal account makes the syntactic derivation more complicated, as it requires both ungrammatical underlying forms and a rule to make them grammatical (Zhang 2009).

2.2. PHRASAL COORDINATION. According to a phrasal analysis of coordination adopted by a number of linguists (Bošković 2009; Johannessen 1996, 1998; Munn 1993, 1999; Zhang 2009), what is being coordinated is NP/DPs. Person, number, and gender features are established via Agree (Chomsky 2000). In a phrasal analysis of coordination, Full Agreement (FA) results from the Spec-head agreement configuration while Closest Conjunct Agreement (CCA) results from the asymmetry of coordination whereby the agreeing head has asymmetric access to one of the prominent conjuncts or its features.

In conjunct agreement, languages can display a number of agreement paradigms based on the position of the verb and the conjunction phrase. Full Agreement (FA) is established when the predicate exhibits agreement features of the conjunction phrase as a whole. Closest Conjunct Agreement (CCA) is observed when the agreement morphology manifests itself on the linearly closer or more prominent conjunct. Finally, Distant Conjunct Agreement (DCA) is when the agreement marking is on the conjunct that is further away from the predicate. These three agreement paradigms are illustrated in Table 1 below. The first column represents the agreement patterns in clauses where the verb follows the conjunction phrase. The second column illustrates the same agreement patterns in clauses where the verb precedes the conjunction phrase. The shaded areas in each cell indicate the features of which conjuncts appear on the verb.

\begin{tabular}{|c|l|l|}
\hline & $\mathrm{C}_{1} \mathrm{C}_{2} \mathrm{~V}$ & $\mathrm{VC}_{1} \mathrm{C}_{2}$ \\
\hline $\mathrm{FA}$ & $\mathrm{C}_{1} \mathrm{C}_{2} \mathrm{~V}$ & $\mathrm{VC}_{1} \mathrm{C}_{2}$ \\
\hline $\mathrm{CCA}$ & $\mathrm{C}_{1} \mathrm{C}_{2} \mathrm{~V}$ & $\mathrm{VC}_{1} \mathrm{C}_{2}$ \\
\hline $\mathrm{DCA}$ & $\mathrm{C}_{1} \mathrm{C}_{2} \mathrm{~V}$ & $\mathrm{VC}_{1} \mathrm{C}_{2}$ \\
\hline
\end{tabular}

Table 1: Agreement patterns based on the structural position of the verb

As illustrated in Table 1, FA can appear both pre-verbally and post-verbally. (7) below shows an instance of FA when the verb follows the conjunction phrase, while (8) illustrates another occurrence of FA when the verb precedes the conjunction phrase. 
(7) Turkish

$\begin{array}{llll}\text { ben } & \text { ve } & \text { o } & \text { yürü-dü-k } \\ \text { I } & \text { and } & \text { s/he } & \text { walk-PAST-1PL }\end{array}$

'I and s/he walked.'

(8) Moroccan Arabic (Benmamoun, Bhatia, \& Polinsky 2009)

žaw Somar w Kariim

came.3PL Somar and Karim

'Omar and Karim came.'

Similarly, CCA can be observed both when the verb follows the CP as in (9); or when it precedes the $\mathrm{CP}(10)$.

(9) Serbo-Croatian (Bošković 2009)

sva sela $i$ sve varošice su uništene

all villages.NEUT and all towns.FEM are destroyed.PL.FEM

'All the villages and towns were destroyed.'

(10) Arabic (Progovac 1998)

gatalen el-banaat we-l-walad el-bisse

killed.PL.FEM the-girls and-the-boy the-cat

'The girls and the boy killed the cat.'

3. Turkish agreement paradigms. Turkish is an Altaic, head-final language. It is agglutinative, and the canonical word order is SOV, although it is flexible as long as the verb agrees with the subject. The table below illustrates the agreement paradigms in Turkish.

\begin{tabular}{|l|c|c|c|c|}
\hline \multirow{2}{*}{} & \multicolumn{2}{|c|}{ Paradigm 1 } & \multicolumn{2}{c|}{ Paradigm 2 } \\
\cline { 2 - 5 } & SINGULAR & PLURAL & SINGULAR & PLURAL \\
\hline 1ST & $-\mathrm{m}$ & $-\mathrm{k}$ & - (y)Im & -(y)Iz \\
\hline 2ND & $-\mathrm{n}$ & $-\mathrm{nIz}$ & - -sIn & -sInIz \\
\hline 3RD & $-\varnothing$ & $-\varnothing /-1 \mathrm{Ar}$ & $-\varnothing$ & $-\varnothing /-1 \mathrm{Ar}$ \\
\hline
\end{tabular}

Table 2: Agreement paradigms in Turkish

The first paradigm is used with verbal predicates ending with either the simple past suffix $-(y) D I$, or the conditional suffix $-(y) s E$. The second paradigm, on the other hand, can be considered as the elsewhere condition since it applies to all other verbal/non-verbal predicates.

\section{Experimental evidence for FA and CCA in Turkish}

4.1. EXPERIMENT I-ACCEPTABILITY JUDGMENT TASK. An acceptability judgment task was administered on Qualtrics ${ }^{3}$ to investigate Turkish native speakers' conjunct agreement preferences. 34 native speakers of Turkish with a mean age of 29.55 participated in Experiment I. The participants were asked to judge 144 sentences on a 5-point Likert scale from completely natural to completely unnatural.

There were four pronoun combinations that made up the conjunction phrases; ben ve o (I

${ }^{3}$ Qualtrics is a software that allows users to share surveys, and questionnaires to collect and analyze data online. 
and $\mathrm{s} / \mathrm{he}$ ); $o$ ve ben ( $\mathrm{s} / \mathrm{he}$ and $\mathrm{I}) ;$ sen ve $o$ (you and $\mathrm{s} / \mathrm{he}) ;$ o ve sen ( $\mathrm{s} / \mathrm{he}$ and you). The conjunction phrases either preceded or followed the verb $\left(\mathrm{C}_{1} \mathrm{C}_{2} \mathrm{~V}\right.$ or $\left.\mathrm{VC}_{1} \mathrm{C}_{2}\right)$. These constructions were tested in 3 agreement paradigms, namely with FA, CCA, and DCA. Four activity verbs (Vendler, 1957) used were gitmek (go); gelmek (come); yürümek (walk); and koşmak (run). Based on those variables, there were 96 experimental items. In addition, 48 distractors testing the proper use of the question particle $-m I$ were used to mask the aim of the experiment. The figure below illustrates the agreement preferences of Turkish native speakers in CPs preceding the verb.

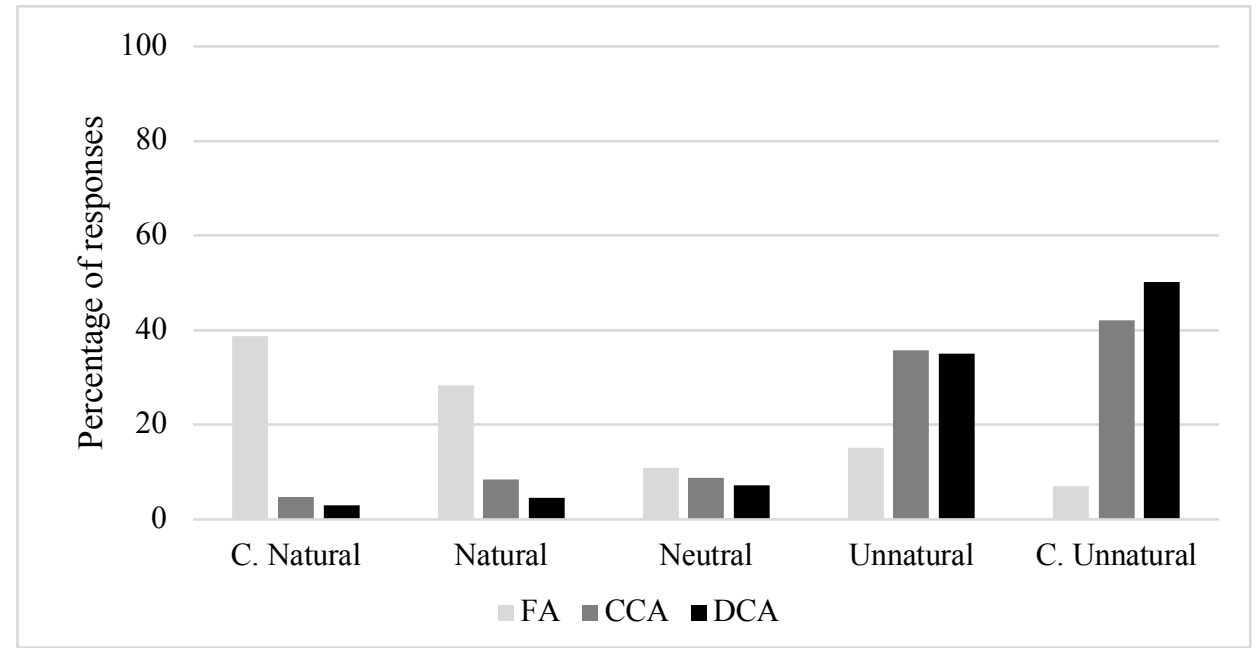

Figure 1. Agreement preferences in CPs preceding the verb $\left(\mathrm{C}_{1} \mathrm{C}_{2} \mathrm{~V}\right)$

The next figure demonstrates the agreement preferences of Turkish native speakers in conjunction phrases following the verb.

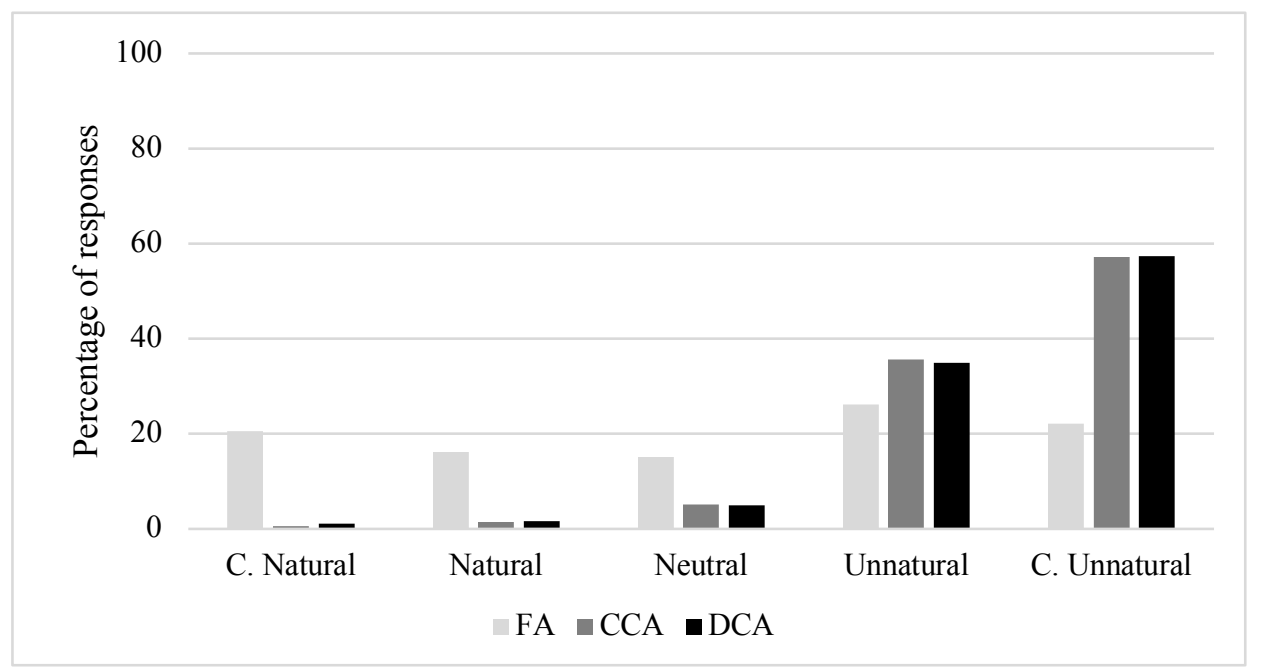

Figure 2. Agreement preferences in CPs following the verb $\left(\mathrm{VC}_{1} \mathrm{C}_{2}\right)$

The results of the first experiment indicate that native speakers of Turkish show a clear preference for FA in CPs while consistently finding CCA and DCA unnatural, with the latter being more dispreferred. Interestingly, the acceptability judgments for the three agreement patterns decrease when the $\mathrm{CP}$ follows the verb, which may be attributed to the fact that Turkish is a canonically SOV language. 
4.2. EXPERIMENT II - FORCED CHOICE TASK. The second experiment, also administered on Qualtrics, investigated if the participants favored either CCA or DCA when they were forced to choose between them and when FA was not available. 20 native speakers of Turkish with a mean age of 28.21 participated in Experiment II. For each item, the participants were presented with two sentences, minimally differing in their agreement morphology, and they were asked to choose the sentence that sounded more natural to them. One sentence exhibited CCA and the other had DCA. Similar to the first experiment, there were four pronoun combinations that made up the conjunction phrases; ben ve o (I and s/he); o ve ben ( $/$ /he and I); sen ve o (you and s/he); $o$ ve sen $\left(\mathrm{s} /\right.$ he and you). The conjunction phrases either preceded or followed the verb $\left(\mathrm{C}_{1} \mathrm{C}_{2} \mathrm{~V}\right.$ or $\mathrm{VC}_{1} \mathrm{C}_{2}$ ). Four activity verbs (Vendler, 1957) used were gitmek (go); gelmek (come); yürümek (walk); and koşmak (run). There were 32 experimental items. In addition, 16 distractors testing the proper use of the question particle $-m I$ were used to mask the aim of the experiment. In total, there were 48 sentences. The figure below illustrates the results of the second experiment.

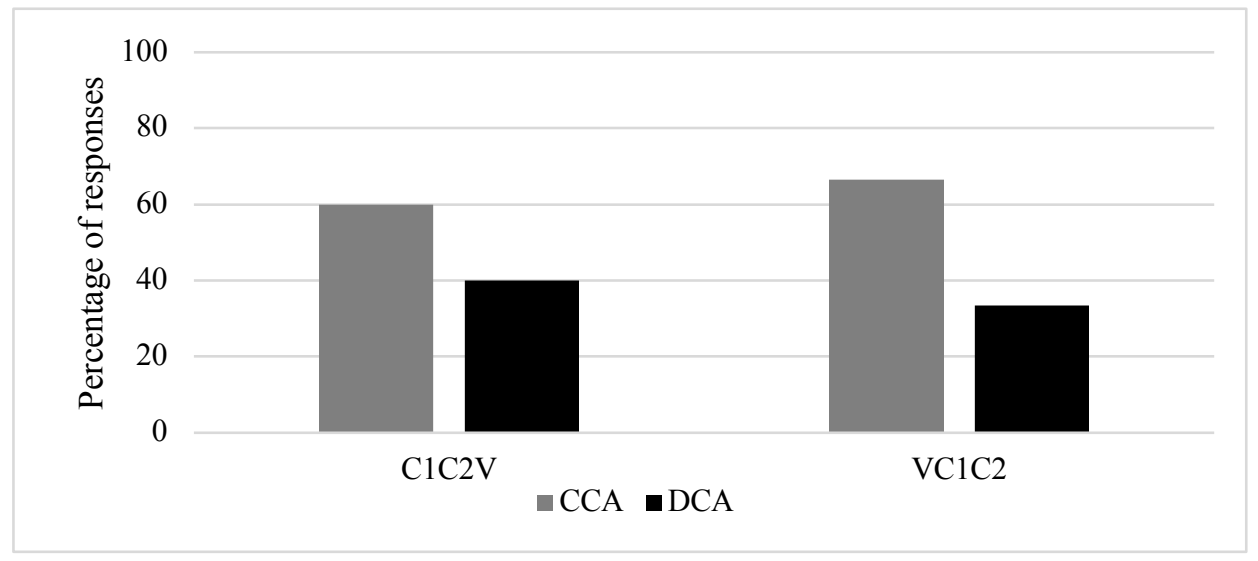

Figure 3. Agreement preferences for CCA and DCA in pre-verbal and post-verbal CPs in a forced choice task

The results of Experiment II indicate that the participants clearly prefer CCA over DCA in both pre-verbal and post-verbal CPs. A separate chi-square analysis for each word order revealed that native speakers of Turkish preferred CCA more often than would be predicted if all the participants were randomly picking either CCA or DCA $\left(p=.048\right.$ for $\mathrm{C}_{1} \mathrm{C}_{2} \mathrm{~V}$ and $p=.001$ for $\left.\mathrm{VC}_{1} \mathrm{C}_{2}\right)$.

5. A compositional view of agreement. I believe that the preference for FA in Experiment I and preference of CCA over DCA in Experiment II provides evidence that conjunct agreement in Turkish takes place in two stages. The first operation that needs to be appealed to is Agree (Chomsky 2000), stated below.

(11) $\alpha$ can Agree with $\beta$ iff:

a. $\alpha$ carries at least one unvalued and uninterpretable feature and $\beta$ carries a matching interpretable and valued feature.

b. $\alpha$ c-commands $\beta$.

c. $\beta$ is the closest goal to $\alpha$.

d. $\beta$ bears an unvalued uninterpretable feature.

Building on Chomsky (2000), Marušič, Nevins, and Badecker (2010) maintain that there are 
three strategies to access the features from the search space determined by the relation Agree. First, agreement features can be accessed maximal-projectionally, where the agreeing head targets the whole coordinated phrase at PF. In such agreement, the resolved features of the whole coordinated phrase are chosen on the predicate. Second, agreement features can be accessed hierarchically. In this pattern, the agreeing head targets the highest conjunct, and hence the features of the highest conjunct are chosen. Finally, features can be accessed linearly. In a linear agreement pattern, the agreeing head targets the linearly closest conjunct, whereby the features of the linearly closest conjunct are chosen on the predicate (Marušič et al., 2010).

In a similar vein, some linguists attribute the different patterns in conjunct agreement to the special status of the PF. To give an example, Ackema and Neeleman (2004) argue that if linear adjacency is involved in CCA, the phenomenon is likely to belong in the PF component. Therefore, even though agreement may take place in the syntax, the way the features are spelled-out may not be faithful to the syntactic component. To be more specific, some features may get altered (Noyer 1992), or a feature may be completely absent (Benmamoun 2000).

5.1. FULL AGREEMENT IN TURKISH. Building on Chomsky (2000) and Marušič et al. (2010), I think the results of Experiment I and II can be accounted for. I argue that FA results from the spec-head agreement with the $\mathrm{CP}$ and the features of both conjuncts are resolved and inherited to the CP (Johannessen 1996). The following example and the corresponding tree diagram show how FA is established in Turkish.

$\begin{array}{llll}\text { a. ben ve o } & \text { git-ti-k } \\ \text { I } \quad \text { and } \quad \text { s/he } & \text { go-PAST-1PL } \\ \text { 'I and s/he went.' } & \end{array}$

b.

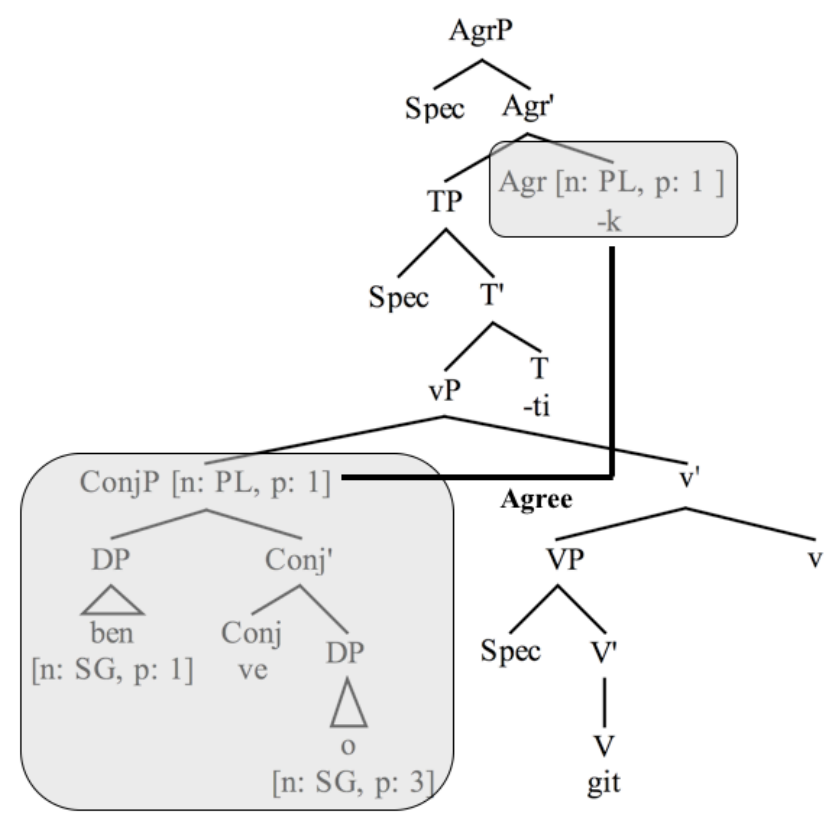

5.2. CLOSEST CONJUNCT AGREEMENT IN TURKISH. In CCA, on the other hand, the agreeing head has asymmetric access to one of the prominent conjuncts or its features (Bošković 2009; Johannessen 1998; Munn 1993, 1999; Benmamoun 1992). It is observed that in another preferred agreement pattern in Turkish, the agreement is with the linearly closest conjunct and the features 
of that conjunct appear on the verb. The examples (13) and (14) below, and the corresponding tree diagrams show how CCA is established in Turkish.
(13)
I and $\mathrm{s} / \mathrm{he}$
go-PAST-3SG
a. ben ve o git-ti- $\varnothing$
'I and s/he went.'

b.

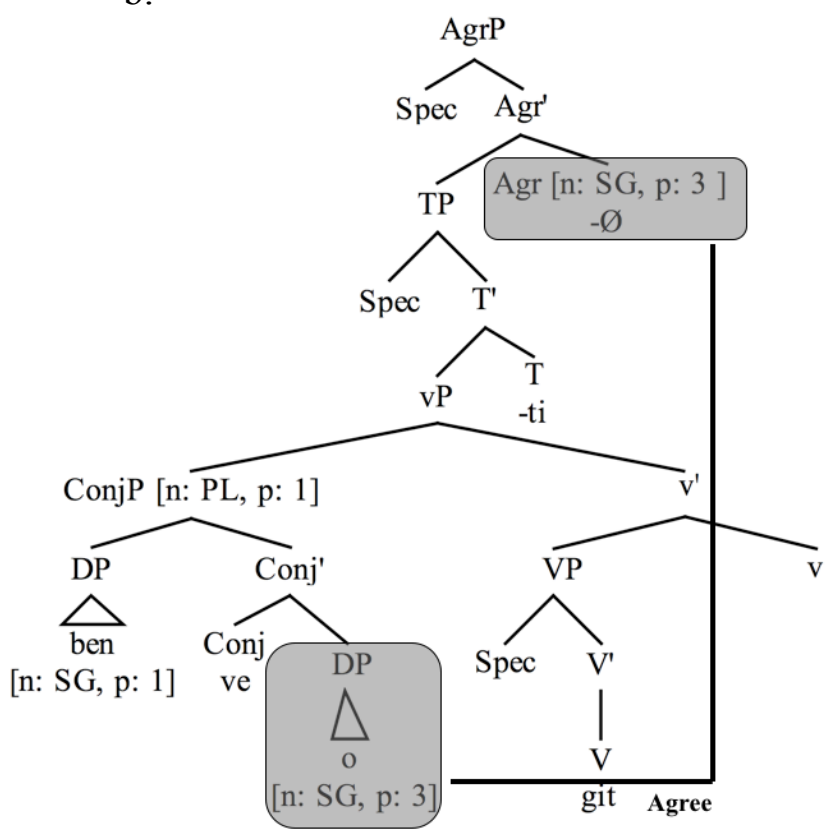

(14)

a. $o$ ve ben git-ti-m

$\mathrm{s} /$ he and I go-PAST-1SG

'I and s/he went.'

b.

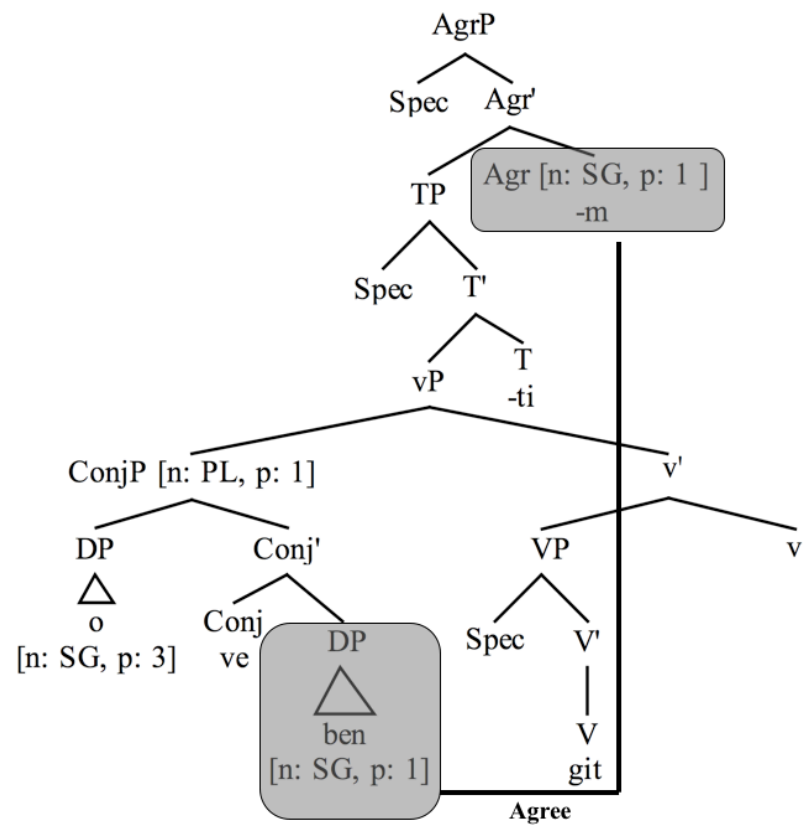


6. Conclusion and future directions. In this article, I presented novel experimental evidence suggesting that conjunct agreement in Turkish is a result of two components. The syntactic component is responsible for the agreement between the probe and the goal in the case of FA while the PF component is responsible for the spelling out of the person and number features of the linearly more proximate conjunct in the case of CCA irrespective of whether the CP precedes or follows the verb (similar accounts can be found in Bhatia 2011; Franck et al. 2002; Ackema and Neeleman 2004; Haskell and MacDonald 2005; Benmamoun and Lorimor 2006; Zhang 2009).

A future direction could be to further investigate the exact nature of FA in Turkish. Consider the minimal pair below, where the $1^{\text {st }}$ person plural agreement is grammatical (15a), while the $3^{\text {rd }}$ person plural agreement renders the construction ungrammatical.

$$
\begin{array}{clll}
\text { a. ben } & \text { ve } & \text { o } & \text { git-ti-k } \\
\text { I } & \text { and } & \text { s/he } & \text { go-PAST-1PL }
\end{array}
$$

'I and s/he went.'

b. ben ve o git-ti-ler

I and $\mathrm{s} / \mathrm{he}$ go-PAST-3PL

'*I and s/he went.'

If FA means that the features of both conjuncts are resolved and inherited to the $\mathrm{CP}$, it is curious why only the $1^{\text {st }}$ person plural agreement is grammatical in (15) since the conjuncts making up the $\mathrm{CP}$ are a first person and a third person pronoun. A possible explanation may be that there are multiple Agree operations, where the agreeing head first selects the resolved number features of the $\mathrm{CP}$ as a whole, subsequently initiating another probe that results in the person agreement features of only one of the conjuncts. That is, future research could look into the exact contribution of phi-features in agreement paradigms in CPs in Turkish.

Future studies could also investigate the proposed analysis in other head final languages, as well as the status of DCA in those languages. Such research has the potential to uncover cross-linguistic differences in the interaction between linear adjacency and agreement paradigms. 


\section{Appendix: Tables from Experiment I and Experiment II}

\section{Experiment I}

\begin{tabular}{|c|c|c|c|c|c|}
\hline & C. Natural & Natural & Neutral & Unnatural & C. Unnatural \\
\hline FA & 38.78 & 28.3 & 10.84 & 15.07 & 6.98 \\
\hline CCA & 4.77 & 8.45 & 8.82 & 35.84 & 42.09 \\
\hline DCA & 2.94 & 4.59 & 7.16 & 35.11 & 50.18 \\
\hline
\end{tabular}

Table 3: Agreement preferences in CPs preceding the verb $\left(\mathrm{C}_{1} \mathrm{C}_{2} \mathrm{~V}\right)$

\begin{tabular}{|c|c|c|c|c|c|}
\hline & C. Natural & Natural & Neutral & Unnatural & C. Unnatural \\
\hline FA & 20.58 & 16.17 & 15.07 & 26.1 & 22.05 \\
\hline CCA & 0.55 & 1.47 & 5.14 & 35.66 & 57.16 \\
\hline DCA & 1.1 & 1.65 & 4.96 & 34.92 & 57.35 \\
\hline
\end{tabular}

Table 4: Agreement preferences in CPs following the verb $\left(\mathrm{VC}_{1} \mathrm{C}_{2}\right)$

\section{Experiment II}

\begin{tabular}{|c|c|c|}
\hline & CCA & DCA \\
\hline $\mathrm{C}_{1} \mathrm{C}_{2} \mathrm{~V}$ & 59.86 & 40.13 \\
\hline $\mathrm{VC}_{1} \mathrm{C}_{2}$ & 66.44 & 33.55 \\
\hline
\end{tabular}

Table 5: Agreement preferences for CCA and DCA in pre-verbal and post-verbal CPs in a forced choice task 


\section{References}

Ackema, Peter, and Ad Neeleman. 2004. Beyond morphology: Interface conditions on word formation. Oxford: Oxford University Press.

Aoun, Joseph, and Elabbas Benmamoun. 1999. Gapping, PF merger, and patterns of partial agreement. In Fragments: Studies in ellipsis and gapping, ed. by Shalom Lappin and Elabbas Benmamoun, 170-187. Oxford: Oxford University Press.

Aoun, Joseph, Elabbas Benmamoun, \& Dominique Sportiche. 1994. Agreement and conjunction in some varieties of Arabic. Linguistic Inquiry 25:195-220.

Benmamoun, Elabbas. 1992. Functional and Inflectional Morphology: Problems of Projection, Representation and Derivation. Doctoral dissertation. University of Southern California, Los Angeles, CA.

Benmamoun, Elabbas. 2000. Agreement Asymmetries and the PF Interface. In Research in Afroasiatic Grammar, ed. by Jacqueline Lecarme, Jean Lowenstamm and Ur Shlonsky, 23-40. Philadelphia: John Benjamins.

Benmamoun, Elabbas and Archna Bhatia. 2010. The structure of coordination and close conjunct agreement. Ms., University of Illinois.

Benmamoun, Elabbas and Heidi Lorimor. 2006. Featureless expressions: When morphophonological markers are absent. Linguistic Inquiry 37:1-23.

Benmamoun, Elabbas and Archna Bhatia, Polinsky, Maria (2009). Closest conjunct agreement in head final languages Linguistic Variation Yearbook 9:67-88.

Bhatia, Archna. 2011. Agreement in the case of coordination: Hindi as a case study. $\mathrm{PhD}$ Dissertation. University of Illinois at Urbana-Champaign.

Bošković, Zeljko. 2009. Unifying first and last conjunct agreement. Natural Language and Linguistic Theory 27:455-496.

Camacho, José. 2003. The Structure of Coordination: Conjunction and Agreement Phenomena in Spanish and Other Languages. Dordrecht: Kluwer Academic Publishers.

Chomsky, Noam. 2000. Minimalist Inquiries: The Framework. In Step by Step: Essays on Minimalist Syntax in honor of Howard Lasnik, ed. by Roger Martin, David Michaels, and Juan Uriagereka, 89-155. Cambridge, MA: MIT Press.

Franck, Julie, Gabriella Vigliocco, and Janet Nicol. 2002. Attraction in sentence production: The role of syntactic structure. Language and Cognitive Processes 4:371-404.

Gazdar, Gerald, E. Klein, Geoffrey Pullum, and Ivan Sag. 1985. Generalized Phrase Structure Grammar. Cambridge, MA: Harvard University Press.

George, Leland 1980. Analogical generalization in natural language syntax. PhD Dissertation. MIT.

Goodall, Grant. 1987. Parallel Structures in Syntax: Coordination, causatives, and restructuring. Cambridge: Cambridge University Press.

Haskell, Todd, and Maryellen MacDonald. 2005. Constituent structure and linear order in language production: Evidence from subject-verb agreement. Journal of Experimental Psychology: Learning, Memory, and Cognition 31:891-904.

Hoekstra, Eric 1994. Expletive replacement, verb-second and coordination. The Linguistic Review 11:285-297.

Hudson, Richard A. 1970. On clauses containing conjoined and plural noun phrases in English. Lingua 3:205-253.

Ingria, Robert J. P. 1990. The limits of unification. Proceedings of the Twenty-Eighth Annual Meeting of the Association for Computational Linguistics 194-204. Pittsburgh, 
Pennsylvania.

Johannessen, Janne Bondi. 1996. Partial Agreement and Coordination. Linguistic Inquiry 27: 661-676.

Johannessen, Janne Bondi. 1998. Coordination. Oxford: Oxford University Press.

Larson, Richard K. 1990. Double Objects Revisited: Reply to Jackendoff. Linguistic Inquiry 21: 589-563.

Marušič, Franc, Andrew Nevins, and William Badecker. 2010. The Grammars of Conjunction Agreement in Slovenian. Accessed at http://ling.auf.net/lingBuzz/001131.

Munn, Alan Boag. 1987. Coordinate Structure and X-bar Theory. McGill Working Papers in Linguistics 4:121-140.

Munn, Alan Boag. 1993. Topics in the Syntax and Semantics of Coordinate Structures. Doctoral dissertation. University of Maryland.

Munn, Alan Boag. 1999. First Conjunct Agreement: Against a Clausal Analysis. Linguistic Inquiry 30:643-668.

Noyer, Rolf. 1992. Features, positions, and affixes in autonomous morphological structure. $\mathrm{PhD}$ dissertation, MIT.

Pollard, Carl and Ivan Sag 1994. Head-Driven Phrase Structure Grammar. Chicago: University of Chicago Press.

Progovac, Ljiljana. 1998. Structure for coordination. Glot International, 3:3-9.

Pullum, Geoffrey and Arnold Zwicky 1986. Phonological resolution of syntactic feature Conflict. Language 62:751-773.

Sag, Ivan A., Gerald Gazdar, Thomas Wasow, and Steven Weisler. 1985. Coordination and How to Distinguish Categories. Natural Language and Linguistic Theory 3:117-171.

Vendler, Zeno. 1957. Verbs and Times. Philosophical Review 56:143-160.

Zhang, Nina Ning. 2010. Coordination in Syntax. Cambridge: Cambridge University Press.

Zoerner, Edward. 1995. Coordination: The Syntax of \&P. Doctoral dissertation. University of California, Irvine. 